\title{
Effect of strains and extraction methods on $\beta$-glucan production, antioxidant properties, and FTIR Spectra from mushroom fruiting bodies of Schizophyllum commune Fr. in Thailand
}

\author{
${ }^{1}$ Mongkontanawat, N. and ${ }^{2 *}$ Thumrongchote, D. \\ ${ }^{1}$ Department of Product Development and Management Technology, Faculty of Agro-Industrial Technology, \\ Rajamangala University of Technology Tawan-Ok, Chanthaburi Campus, Chanthaburi, Thailand 22210. \\ ${ }^{2}$ Department of Food Technology and Nutrition, Faculty of Home-Economics Technology, Rajamangala \\ University of Technology Krungthep, 149 Chareankrung Rd., Yannawa, Sathorn, Bangkok, Thailand 10120.
}

\author{
Article history: \\ Received: 12 April 2021 \\ Received in revised form: 25 \\ May 2021 \\ Accepted: 28 May 2021 \\ Available Online: 31 August \\ 2021
}

Keywords:

Schizophyllum commune Fr., Mushroom fruiting bodies,

Schizophyllum commune $\mathrm{Fr}$ polysaccharide,

$\beta$-glucan,

$\beta$-glucan extraction method, FTIR Spectra

DOI:

https://doi.org/10.26656/fr.2017.5(4).259

\begin{abstract}
Schizophyllum commune Fr., a native mushroom of Thailand, has a high nutritional value and is classified as a mushroom with medicinal properties that can neutralize the growth of many cancer cells. This research aimed to study the effect of $S$. commune strains and the extraction methods on the quantity and properties of $\beta$-glucan. The five $S$. commune Fr. strains used in this research consisted of Chanthaburi, 85-022, 85-023, 85-031, and 85043 . There were two different $\beta$-glucan extraction methods employed: hot water (M1) and hot alkali extraction (M2), which were compared with the control (native-MR). The results indicated that the Chanthaburi strain has the highest $\beta$-glucan content $49.20 \pm 0.35 \%$ $(\mathrm{w} / \mathrm{w})$, and high potential antioxidant activity $(79.14 \pm 0.77 \mathrm{DPPH} \%$ and $50.92 \pm 0.48$ ABTS\%) $(\mathrm{p}<0.05)$. The extraction methods did not affect the yield of $\beta$-glucan, except the antioxidant properties and chemical structure of the extract substance. The extract substance from M2 has significantly the highest potential antioxidant activity (80.22 \pm 0.51$)$. A mushroom juice drink in cans was developed using 1-day-old MR and adjusted $\mathrm{pH}$ of more than 7 , which can increase the antioxidant properties of the product.
\end{abstract}

\section{Introduction}

Schizophyllum commune Fr., an edible mushroom, is a native mushroom that grows on logs in Thailand's forests. Its common local name is "Krang", and Thai people, especially in the South, prefer to eat Krang mushrooms, which are found in sour soup or coconut milk curry, because of the good unique taste and high nutritional value (Basso et al., 2020). Schizophyllum commune Fr. contains Schizophyllan ( $\beta$-1, 3-glucan), an anticancer substance (Lemieszek and Rzeski, 2012), and antioxidant compounds that have anti-ageing properties (Pirshahid et al., 2011). The chemical composition of substrate produced from $S$. commune influenced $\beta$ glucan content, phenolic content, and antioxidant activity (Klaus et al., 2011; Basso et al., 2020). Schizophyllum commune is grown in different regions and has various chemical compositions. It was reported that $S$. commune (MCCT 38) in Tripura, India consisted of $15.55 \%$ crude protein, $42 \%$ total carbohydrates and $30.0 \%$ crude fibre (Debnath et al., 2017), which differs from the $S$. commune (MCCT 38) in Nagaland, India that consisted of $22.50 \%$ crude protein, $32.43 \%$ total carbohydrates and
$6.50 \%$ crude fibre (Kumar et al., 2013). Nevertheless, there is currently no information about the effect of $S$. commune Fr. strains on the $\beta$-glucan production and the effect of the extraction method on the antioxidant properties of $\beta$-glucan from $S$. commune Fr. The aim of this research had two objectives, the first of which focuses on the selection of the strains of $S$. commune $\mathrm{Fr}$ for $\beta$-glucan production. The second objective is the investigation of the effect of extraction methods on the amount of $\beta$-glucan production and its antioxidant properties. The results will be beneficial in many industries, such as the food, pharmaceutical or cosmetics industries, especially local food production from natural mushrooms. This research is an adaptation of the extraction method of $\beta$-glucan by using filtering instead of centrifugation, which is a low-cost technology that can be implemented by the community.

\section{Materials and methods}

\subsection{Materials}

Five pure mycelial culture strains of $S$. commune $\mathrm{Fr}$ were obtained from a Chanthaburi mushroom farm (1 
strain), and the Department of Agriculture (4 strains), Thailand. The culture collection number from the Chanthaburi mushroom farm was Chanthaburi, and the Department of Agriculture was 85-022, 85-023, 85-031, and $85-043$. The mycelium was grown on sterile culture food bags at $30^{\circ} \mathrm{C}$ for 7 days or until the mushroom fibres start to gather and grow into a mushroom. The sample used in the experiment included 1-day-old mushroom fruiting bodies, which came from the preliminary experiment; it was found that the mushroom fruiting bodies had higher glucan content than the mushroom mycelium and the 1-day mushroom fruiting bodies had the most. The mushroom samples were dried in a hot air oven at $70 \pm 5^{\circ} \mathrm{C}$ until reaching $2.50 \pm 0.02 \%$ moisture content. The dry samples were ground, sifted through an 80 mesh sieve, and stored at room temperature in aluminium bags for further analysis.

\subsection{Glucan content determination}

The Glucan contents were determined by using a $\beta$ Glucan Assay Kit (Megazyme International, Wicklow, Ireland). The principle of the $\beta$-Glucan (Yeast and Mushroom) Assay Kit is based on the determination of total glucan, which consists of $\alpha$-Glucan and $\beta$-Glucan linkages. The bonds of $(1 \rightarrow 3,1 \rightarrow 6)-\beta$ - D-Glucan, $(1 \rightarrow 3)-\beta$-Glucan and $\alpha$-Glucan were dissolved and cut by concentrate hydrochloric acid at $100^{\circ} \mathrm{C}$ for $2 \mathrm{hrs}$, then the solution was incubated with exo-1, $3-\beta$ glucanase and $\beta$-glucosidase in order to obtain complete $D$-glucose for analysis of total glucan content. For $\alpha$ Glucan, it was digested to be glucose with amyloglucosidase plus invertase, using the GOPOD reagent to measure glucose content.

\subsubsection{Total glucan content}

For the total glucan content, $10 \mathrm{mg}$ of native-MR powder was placed in Eppendorf tubes, then $0.15 \mathrm{~mL}$ of $37 \%$ hydrochloric acid was added. The solution was mixed and incubated at $30^{\circ} \mathrm{C}$ for 45 mins (vortexed every $15 \mathrm{mins}$ ). Then, $1 \mathrm{~mL}$ of distilled water was added, mixed and incubated at $100^{\circ} \mathrm{C}$ for $2 \mathrm{hrs}$ before adding $0.5 \mathrm{~mL}$ of $4 \mathrm{M} \mathrm{KOH}$. The $200 \mu \mathrm{L}$ solution was taken and adjusted for volume to $1 \mathrm{~mL}$ with sodium acetate buffer $\mathrm{pH} 5(800 \mu \mathrm{L})$ and mixed. After that, the mixtures were centrifuged at $13,000 \times g$ for 5 mins. Samples $(20 \mu \mathrm{L})$ were placed into each well (in duplicates) before adding $10 \mu \mathrm{L}$ of a mixture of exo-1,3- $\beta$-glucanase plus $\beta$ glucosidase and then incubated at $37^{\circ} \mathrm{C}$ for 90 mins. Finally, $200 \mu \mathrm{L}$ of glucose oxidase/peroxidase was added followed by incubation at $37^{\circ} \mathrm{C}$ for 30 mins. The absorbance was measured at $510 \mathrm{~nm}$ with a spectrophotometer. The amount of total glucan content was calculated with Equation (1).
Total Glucan $(\% \mathrm{w} / \mathrm{w})=\Delta \mathrm{E} \times \mathrm{F} / \mathrm{W} \times 90$

Where $\Delta \mathrm{E}$ is the absorbance, $\mathrm{F}$ is the factor to convert the absorbance to $\mu \mathrm{g}$ of D-glucose, and $\mathrm{W}$ is the weight of the sample (g).

\subsection{2 $\alpha$-glucan and $\beta$-glucan content}

For the $\alpha$-glucan content, $100 \mathrm{mg}$ of native-MR powder was placed in test tubes. Then, $2 \mathrm{M} \mathrm{KOH}(2 \mathrm{~mL})$ was added and the pellets were stirred with a magnetic stirrer in the ice bath for 20 mins, and after, $8 \mathrm{~mL}$ of 1.2 $\mathrm{M}$ sodium acetate buffer ( $\mathrm{pH}$ 3.8) was added to the mixture. Then, $1 \mathrm{~mL}$ of the sample was placed into an Eppendorf tube, and $20 \mu \mathrm{L}$ of Amyloglucosidase plus invertase was added, followed by incubation at $40^{\circ} \mathrm{C}$ for 30 mins. Next, the mixture was centrifuged at $13,000 \times g$ for 5 mins. Supernatants $(20 \mu \mathrm{L})$ were placed into the microtiter plate. Glucose oxidase/peroxidase $(200 \mu \mathrm{L})$ was added to each well and incubated at $37^{\circ} \mathrm{C}$ for 30 mins. The absorbance was measured at $510 \mathrm{~nm}$ with a spectrophotometer. The amount of $\alpha$-glucan content calculated from Equations (2) or (3) depends on the $\alpha$ glucan content. The $\beta$-glucan content was calculated from total glucan minus $\alpha$-glucan, as shown in Equation (4)

$\alpha$-glucan $>10 \%(\mathrm{w} / \mathrm{w}) ; \alpha$-Glucan $(\% \mathrm{w} / \mathrm{w})=\Delta \mathrm{E} \times$

$\mathrm{F} / \mathrm{W} \times 90$

$\alpha$-glucan $<10 \%(\mathrm{w} / \mathrm{w}) ; \alpha$-Glucan $(\% \mathrm{w} / \mathrm{w})=\Delta \mathrm{E} \times$

$\mathrm{F} / \mathrm{W} \times 9.27$

Where $\Delta \mathrm{E}$ is the absorbance, $\mathrm{F}$ is the factor to convert the absorbance to $\mu \mathrm{g}$ of D-glucose, and $\mathrm{W}$ is the weight of sample $(\mathrm{g})$.

$\beta$-Glucan $(\% \mathrm{w} / \mathrm{w})=$ Total Glucan $(\% \mathrm{w} / \mathrm{w})-[\alpha-$ glucan] $(\% \mathrm{w} / \mathrm{w})$

\subsection{Total phenolic compounds determination}

The total phenolic content was determined with a modified method from Iqbal et al. (2005). Briefly, $3 \mathrm{~g}$ of native-MR powder was mixed with $30 \mathrm{~mL}$ of $80 \%$ ethanol (w/v). The mixture was shaken at $150 \mathrm{rpm}$ for 24 hrs at room temperature. Then, the supernatant was filtered through Whatman filter paper No. 1. The reaction mixture contained $50 \mu \mathrm{L}$ of clear soluble, 200 $\mu \mathrm{L}$ of freshly prepared diluted Folin-Ciocalteu reagent from Merck, and $0.5 \mathrm{~mL}$ of $7.5 \%$ sodium carbonate. The final mixture was diluted to $7 \mathrm{~mL}$ with deionized water. The mixtures were kept in dark at room temperature for $2 \mathrm{hrs}$ to complete the reaction then the absorbance was analysed at $760 \mathrm{~nm}$. Gallic acid was used as a standard. The total phenolic content of the sample was calculated as gallic acid equivalents per $g$ dry weight of extraction. 
The reaction was conducted in triplicate and the results were averaged.

\subsection{ABTH scavenging assay}

The ABTH radical scavenging activities were modified from the assay method of Iqbal et al. (2005). To prepare the ABTS radical cation, $2.45 \mathrm{mM}$ of potassium persulfate (Merck, Germany) aqueous solution was added with $5 \mathrm{mM}$ ABTS (Sigma-Aldrich, Germany) aqueous solution in equal quantities. The mixtures were kept in dark at room temperature for $24 \mathrm{hrs}$ to complete the reaction. Then, $1 \mathrm{~mL}$ of the solution was diluted with $60 \mathrm{~mL}$ ethanol and used in the ABTS test. Next, $0.1 \mathrm{~mL}$ of the extraction solution was added to $2 \mathrm{~mL}$ of ABTS ${ }^{+*}$ solution and kept in the dark at room temperature for 10 min to complete the reaction. The absorbance was measured at $734 \mathrm{~nm}$. The scavenging effect of the ABTS free radicals was calculated as follow:

Inhibition $(\%)=\left[\left(\mathrm{A}_{\text {control }}-\mathrm{A}_{\text {sample }}\right) / \mathrm{A}_{\text {control }}\right] \times 100$

\subsection{DPPH scavenging assay}

The DPPH radical scavenging activities were the ability to reduce the free radical 2, 2 -diphenyl-1picrylhydrazyl radical (DPPH, Sigma). The DPPH radical scavenging activity was modified from the assay method of Iqbal et al. (2005). Briefly, $2 \mathrm{~mL}$ of the extraction solution in No. 2.2.2 was mixed with $2 \mathrm{~mL}$ of $0.2 \mathrm{mM}$ DPPH in ethanol and kept in dark at room temperature for $30 \mathrm{~min}$ to complete the reaction. The absorbance was measured at $517 \mathrm{~nm}$. The scavenging effect of DPPH free radicals was calculated using Equation (5).

\subsection{Effect of extraction method}

The 1-day-old mushroom fruiting bodies of the $S$. commune Fr. strain, which has high glucan content, was selected for this study of the effect of the extraction methods. An accurate weight of $20 \mathrm{~g}$ of the native-MR dried powder was dissolved in $200 \mathrm{~mL}$ of deionized water, and then, the mixture solution was heated at $121^{\circ}$ $\mathrm{C}$ for 15 mins. After that, the sample was allowed to cool down to $45^{\circ} \mathrm{C}$ and the clear part was extracted from the residue by filtering with Whatman paper No 1 . The clear part solution was divided into two parts for comparison of the effect of the extraction method. For Method 1, part 1 was added with absolute ethanol into the ratio 3:1 ethanol/clear part and left overnight at $-20^{\circ} \mathrm{C}$, the clear part was extracted from the residue by filtering with Whatman paper No 1 . The residue was washed with $80 \%$ ethanol three times and dried in a hot air oven at $80^{\circ} \mathrm{C}$ for $3 \mathrm{hrs}$ and grounded to powder (M1 sample) for analysis. For Method 2, part 2 was added with $100 \mathrm{~mL}$ of $1 \mathrm{M} \mathrm{NaOH}$, and the mixture solution was heated at $100^{\circ}$
C for $24 \mathrm{hrs}$, the clear part was extracted from the residue by filtering with Whatman paper No 1. The residue was washed with $80 \%$ ethanol three times. The precipitate was dried in a hot air oven at $80^{\circ} \mathrm{C}$ for $3 \mathrm{hrs}$ and grounded to powder (M2 sample) for analysis. A schematic diagram of the extraction process of polysaccharides by various extraction methods is shown in Figure 1. The dried residues from Method 1 and Method 2 were analyzed for glucan content by using the method in No. 2.2.1, and antioxidant properties by using the methods in No. 2.2.2, No. 2.2.3, and No. 2.2.4 in order to compare them with the control (native-MR dry power).

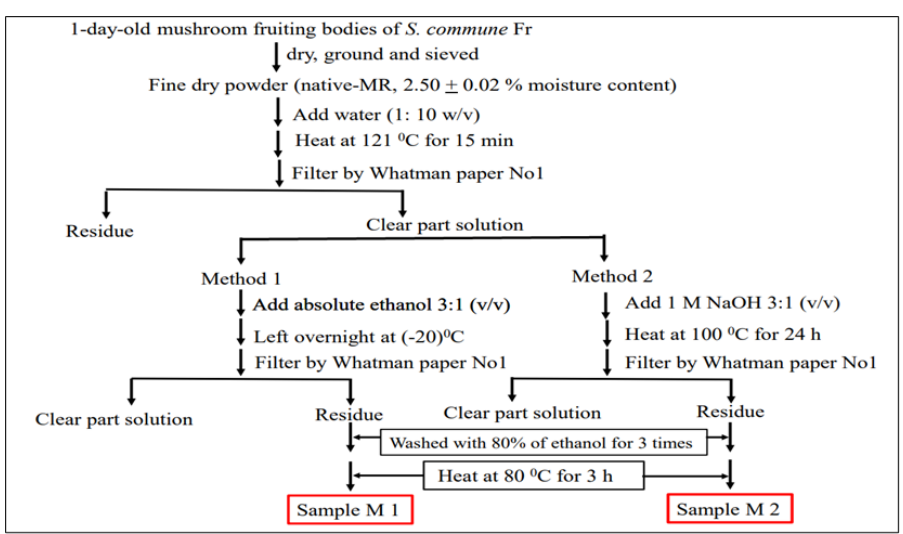

Figure 1. A schematic diagram of the extraction process of polysaccharides by different extraction methods from Schizophyllum commune $\mathrm{Fr}$

\subsection{Chemical structure of extraction substrate}

The FT-IR absorption spectra of extraction substrate samples, from both the M1 and M2 methods, were measured using a Frontier Transform Infrared Spectrometer (FT-IR) (PerkinElmer, model NIRA, Massachusetts, USA). The method used was FT-IR on $\mathrm{KBr}$ solid samples. The $100-200 \mathrm{mg}$ of $\mathrm{KBr}$ was pulverized using an agate mortar and pestle, and mixed with $2 \mathrm{mg}$ of the sample. The mixtures were compressed with a pressure of 10 tons into tablet form for measurement with FT-IR. Each sample's spectrum was collected using reflectance mode, in a scanning range of $400-4000 \mathrm{~cm}^{-1}$, and an accumulation of 60 scans. The FT -NIR spectra of each type were recorded with three replicates.

\subsection{Statistical analysis}

The data were collected from triplicates. Analysis was performed by statistical package SPSS 17 for Windows, and $\mathrm{p}<0.05$ (two-tailed) was considered as statistically significant. All of the data were analyzed with Analysis of Variance (ANOVA) and multiple comparison F-test. 


\section{Results}

\subsection{Production of $\beta$-glucan}

$\beta$-glucan is a substance that has antitumor and antimicrobial properties (Manzi and Pizzoferrato, 2000), and a reduction of blood cholesterol and glucose levels (Nicolosi et al., 1999). Therefore, in this research, 1-dayold $S$. commune Fr. mushroom fruiting bodies (nativeMR) dried powder from five strains was selected: Chanthaburi, 85-022, 85-023, 85-031, and 85-043, which are found in Thailand, for $\beta$-glucan production. The results in Table 1 show that the native-MR dried powder from the Chanthaburi strain was significantly the highest in total-glucan content at $49.76 \pm 0.35 \%(\mathrm{w} / \mathrm{w})$ and $\beta$ glucan content at $49.20 \pm 0.35 \%(\mathrm{w} / \mathrm{w})(\mathrm{p}<0.05)$. The strain of $S$. commune Fr. affects the amount of totalglucan and $\beta$-glucan similar to that of Hypsizygus marmoreus (Mongkontanawat and Wongekalak, 2015) and $S$. commune Fr. mushrooms from local markets in Chanthaburi province, Thailand. (Mongkontanawat and Phuangborisut, 2015).

Table 1. Mean of glucan content of native-MR dried powder from $S$. commune Fr, which different strains.

\begin{tabular}{lccc}
\hline Samples Strain & $\begin{array}{c}\text { Total-glucan } \\
\text { Content } \\
(\% \mathrm{w} / \mathrm{w})\end{array}$ & $\begin{array}{c}\alpha \text {-glucan } \\
\text { Content } \\
(\% \mathrm{w} / \mathrm{w})\end{array}$ & $\begin{array}{c}\beta \text {-glucan } \\
\text { Content } \\
(\% \mathrm{w} / \mathrm{w})\end{array}$ \\
\hline Chanthaburi & $49.76 \pm 0.35^{\mathrm{a}}$ & $0.56 \pm 0.01^{\mathrm{a}}$ & $49.20 \pm 0.35^{\mathrm{a}}$ \\
$85-022$ & $48.84 \pm 0.24^{\mathrm{b}}$ & $0.41 \pm 0.05^{\mathrm{b}}$ & $48.43 \pm 0.23^{\mathrm{b}}$ \\
$85-023$ & $48.63 \pm 0.18^{\mathrm{b}}$ & $0.56 \pm 0.01^{\mathrm{a}}$ & $48.07 \pm 0.20^{\mathrm{b}}$ \\
$85-031$ & $48.51 \pm 0.12^{\mathrm{b}}$ & $0.57 \pm 0.17^{\mathrm{a}}$ & $47.94 \pm 0.09^{\mathrm{b}}$ \\
$85-043$ & $48.67 \pm 0.24^{\mathrm{b}}$ & $0.54 \pm 0.07^{\mathrm{a}}$ & $48.13 \pm 0.24^{\mathrm{b}}$ \\
\hline
\end{tabular}

Values are presented as mean \pm SD of three replications. Values with different superscript within the same column are significantly different $(\mathrm{p}<0.05)$.

The result of total phenolic compounds, DPPH, and ABTH are shown in Table 2. The Chanthaburi, 85-022, 85-023, 85-031, and 85-043 strains were analyzed for total phenolic compounds content by the Folin-Ciocalteu Colorimetric method, DPPH by the DPPH scavenging assay, and ABTH by the ABTH scavenging assay. The results showed that the strain of $S$. commune Fr. had no significant effect on total phenolic compounds content ( $\mathrm{p}$ $>0.05$ ). The $S$. commune Fr. from the Chanthaburi strain had significantly the highest DPPH $(78.98 \pm 0.35 \%)$ and ABTS $(50.92 \pm 0.48 \%)$ compared to that of the other strains $(p<0.05)$. From the results of this experiment, it was indicated that the strain of $S$. commune Fr. affected the $\beta$-glucan production and its chemical composition. The $S$. commune Fr. from the Chanthaburi strain was the most suitable for use as a raw material for $\beta$-glucan production. Therefore, Chanthaburi strain was selected for the study on the effect of extraction methods on the amount and quality of $\beta$-glucan.
Table 2. Total phenolic content and antioxidant properties of $S$. commune Fr from 1-day-old MFB dried powder, which different strains.

\begin{tabular}{lccc}
$\begin{array}{l}\text { Samples } \\
\text { Strain }\end{array}$ & DPPH (\%) & ABTS (\%) & $\begin{array}{c}\text { Total Phenolic } \\
\text { content (mg gallic }\end{array}$ \\
\hline Chanthaburi & $78.98 \pm 0.35^{\mathrm{a}}$ & $50.92 \pm 0.48^{\mathrm{a}}$ & $2.62 \pm 0.18$ \\
$85-022$ & $78.06 \pm 0.36^{\mathrm{b}}$ & $49.92 \pm 0.58^{\mathrm{c}}$ & $2.60 \pm 0.09$ \\
$85-023$ & $78.35 \pm 0.71^{\mathrm{b}}$ & $49.79 \pm 0.47^{\mathrm{c}}$ & $2.60 \pm 0.17$ \\
$85-031$ & $78.29 \pm 0.49^{\mathrm{b}}$ & $50.43 \pm 0.53^{\mathrm{b}}$ & $2.64 \pm 0.16$ \\
$85-043$ & $78.12 \pm 0.45^{\mathrm{b}}$ & $49.62 \pm 0.43^{\mathrm{c}}$ & $2.54 \pm 0.21$ \\
\hline
\end{tabular}

\section{${ }^{\text {ns }}$ Not significant.}

Values are presented as mean \pm SD of three replications. Values with different superscript within the same column are significantly different $(\mathrm{p}<0.05)$

\subsection{Effect of $\beta$-glucan extraction method}

In this research, the objective was to study the effect of the extraction methods on the obtained glucan content and antioxidant properties, which will lead to the development of community canned mushroom juice products from $S$. commune Fr. in Thailand. The filter paper method was chosen instead of sedimentation by centrifugation to extract the glucan. $\beta$-glucan content $(\%$, $\mathrm{db})$ of the M1 extraction substrate, the M2 extraction substrate, and the dried native-MR (control) was analyzed using the Beta Glucan (Yeast and Mushroom) Assay Kit from Megazyme International, as shown in Table 3. The $\beta$-glucan content in the M1 extraction substrate, M2 extraction substrate, and dried native-MR (control) were 48.90\%, 49.23\%, and 49.20\%, respectively, which are high compared with the $\beta$-glucan content in the edible mushrooms (4.71 to $46.20 \% \mathrm{db}$ ) as found by Lee and Kim (2005). Most of the glucan content in both dried extraction substrates and nativeMR dried powder were $\beta$-glucan $(48.90-49.23 \mathrm{~g} / 100 \mathrm{~g}$ of native-MR dried powder), which is consistent with the research of Klaus et al. (2011), who studied antioxidative activities and chemical characterization of polysaccharides extracted from the basidiomycete $S$. commune, which grows on Mountain Avala, Republic of Serbia. The extraction methods had no significant effect on the amount of total-glucan, $\alpha$-glucan, and $\beta$-glucan of the extraction substrates $(p>0.05)$, but had an effect on the antioxidant properties and chemical structure of the extraction substrates, as shown in Table 4 and Figure 2. Table 4 shows that the extraction method affected the antioxidant properties of extracts. The extract from the M2 method had significantly the highest DPPH $(80.22 \pm 0.51 \%)$ and ABTS $(58.16 \pm 0.53 \%)(\mathrm{p}<0.05)$.

FT-IR spectroscopy is a technique that is used in the structural analysis of polysaccharides. The FT-IR spectra shows the molecular vibrations of covalent bonds at the infrared region range $\left(4000-400 \mathrm{~cm}^{-1}\right)$. Figure 2 shows 
Table 3. Mean of glucan content of $S$. commune Fr from 1-day -old MFB dried powder, which different extraction methods.

\begin{tabular}{cccc}
\hline Extraction method & $\begin{array}{c}\text { Total-glucan } \\
\text { Content } \\
(\% \mathrm{w} / \mathrm{w})\end{array}$ & $\begin{array}{c}\alpha \text {-glucan } \\
\text { Content }^{\text {ns }} \\
(\% \mathrm{w} / \mathrm{w})\end{array}$ & $\begin{array}{c}\beta \text {-glucan } \\
\text { Content }^{\mathrm{ns}} \\
(\% \mathrm{w} / \mathrm{w})\end{array}$ \\
\hline Control (native-MR) & $49.76 \pm 0.35$ & $0.56 \pm 0.01$ & $49.20 \pm 0.35$ \\
M1 & $49.47 \pm 0.18$ & $0.57 \pm 0.04$ & $48.90 \pm 0.21$ \\
M2 & $49.76 \pm 0.12$ & $0.53 \pm 0.01$ & $49.23 \pm 0.11$ \\
\hline
\end{tabular}

${ }^{\mathrm{ns}}$ Not significant.

Values are presented as mean \pm SD of three replications.

Table 4. Total phenolic content and antioxidant properties of S. commune Fr from 1-day-old MFB dried powder, which different extraction methods.

\begin{tabular}{cccc}
\hline $\begin{array}{c}\text { Extraction } \\
\text { method }\end{array}$ & DPPH (\%) & ABTS (\%) & $\begin{array}{c}\text { Total Phenolic } \\
\text { content (mg gallic }\end{array}$ \\
\hline $\begin{array}{c}\text { Control } \\
\text { (native-MR) }\end{array}$ & $78.98 \pm 0.35^{\mathrm{b}}$ & $50.92 \pm 0.48^{\mathrm{c}}$ & $2.62 \pm 0.18$ \\
M1 & $80.15 \pm 0.51^{\mathrm{a}}$ & $57.51 \pm 0.48^{\mathrm{b}}$ & $2.90 \pm 0.15$ \\
M2 & $80.22 \pm 0.51^{\mathrm{a}}$ & $58.16 \pm 0.53^{\mathrm{a}}$ & $2.87 \pm 0.06$ \\
\hline
\end{tabular}

${ }^{\text {ns }}$ Not significant.

Values are presented as mean \pm SD of three replications. Values with different superscript within the same column are significantly different $(\mathrm{p}<0.05)$.

the FT-IR absorption spectra of M1 and M2 dried extraction substrate compared with the dried native-MR (control). The infrared absorption characteristics of polysaccharides indicate that both of the extraction methods affected the chemical structure of the extracted substrate when compared with the control sample, especially at the frequency ranges of $1567-1570 \mathrm{~cm}^{-1}$, $1405-1409 \mathrm{~cm}^{-1}$, and $878-876 \mathrm{~cm}^{-1}$.

The results showed that heat and alkalinity had an effect on the structure and antioxidant properties of $S$. commune Fr. $\beta$-glucan, which is consistent with the research of Polacios et al. (2012) and Gieroba et al. (2020). Polacios et al. (2012) found that the extraction method influenced the structure of the polysaccharide extracted from Pleuratus ostreatus fruiting bodies. The extracted polysaccharides structure of Pleuratus ostreatus fruiting bodies with cold water was formed by $\alpha(1 \rightarrow 3,1 \rightarrow 6)$ linked galactopyranosyl residues, whereas the extracted polysaccharides structure with hot water and with hot aqueous $\mathrm{NaOH}$ consisted of glucose-linked units, and the molecular arrangement by complexation with Congo red of $\beta$-linked polysaccharide from hot aqueous $\mathrm{NaOH}$ displayed a triple helix conformation. The $(1 \rightarrow 3)$ - $\beta$ - D- glucan polymer gelled at $80^{\circ} \mathrm{C}$ has a distinctly different structure than the matrix gelled at $90^{\circ}$ C (Gieroba et al., 2020). The important FT-IR absorption spectra region of the extracted polysaccharides from $S$. commune Fr. consisted of the sugar region (1200 - 950 $\mathrm{cm}^{-1}$ ) and anomeric region $\left(950-750 \mathrm{~cm}^{-1}\right)$, and the heat used for extraction or the $\mathrm{pH}$ affected the structure of the extracted $\beta$-glucan. The differences in the chemical structure of the extracted $\beta$-glucan led to different antioxidant properties.

\section{Conclusion}

The research found that the strains of $S$. commune Fr. in Thailand have an effect on the amount of extracted $\beta$ glucan. The 1-day-old MR $S$. commune Fr. from Chanthaburi was proved to be a good source for $\beta$-glucan production. For the effect of the extraction method, it was found that temperature and $\mathrm{pH}$ in the extraction have an effect on the structure and antioxidant properties of $\beta$ glucan. The extraction from 1-day-old MR S. commune Fr. from Chanthaburi with $1 \mathrm{M}$ of $\mathrm{NaOH}$ at $100^{\circ} \mathrm{C}$ for 24 $\mathrm{h}$ yielded $\beta$-glucan with more antioxidant properties than $\beta$-glucan from hot water extraction at $121^{\circ} \mathrm{C}$ for 15 mins.

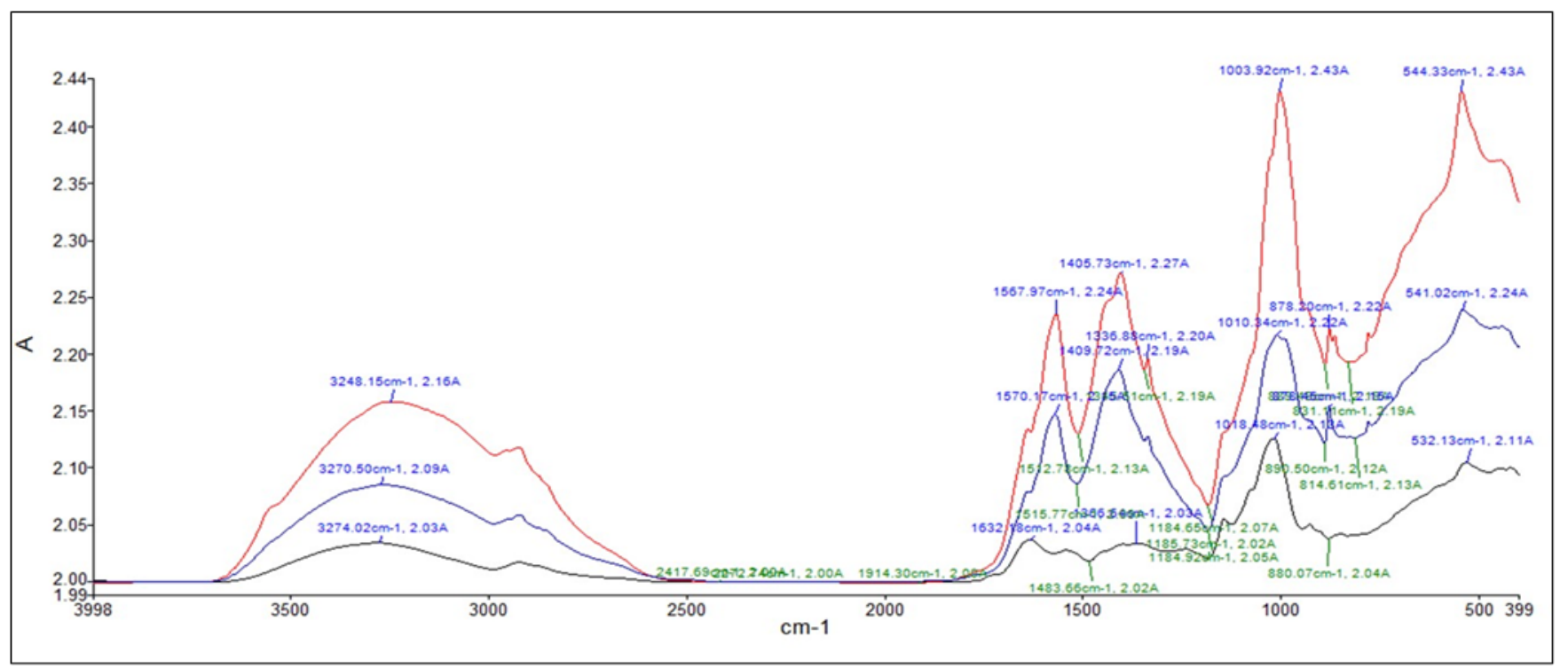

Figure 2. Infrared spectra of S. commune Fr from 1-day-old MFB dried powder, which different extraction method. Red line: M1 method (Hot water extraction method), Blue line: M2 method (Hot water- Hot alkali extraction method), Black line: Control (native-MR dried powder) 
The results of this research led to the development of a ready-to-drink mushroom juice in cans by using 1-dayold MR $S$. commune Fr. and adjusting the $\mathrm{pH}$ to more than 7 , which can increase the antioxidant properties of the product.

\section{Conflicts of interest}

The authors declare no conflict of interest. The funders had no role in the design of the study; in the collection, analyses, or interpretation of data; in the writing of the manuscript, or in the decision to publish the results.

\section{Acknowledgements}

The authors gratefully acknowledge the technical assistance of Ms Sonsri Toikham.

\section{References}

Basso, V., Schiavenin, C., Mendnca, S., Goncalves de Siqueira, F., Salvador, M. and Camassola., M. (2020). Chemical features and antioxidant profile by Schizophyllum commune produced on different agroindustrial wastes and byproducts of biodiesel production. Food Chemistry, 329, 127089. https:// doi.org/10.1016/j.foodchem.2020.127089

Debnath, S., Saha, A. K. and Das, P. (2017). Biological activities of Schizophyllum commune Fr. A wild Edible mushroom of Tripura, North East India. Journal of Mycopathological Research, 54(4), 469475.

Gieroba, B., Sroka-Bartnicka, A., Kazimierczak, P., Kalisz, G., Pieta, I S., Nowakowski, R., Pisarek, M. and Przekora, A. (2020). Effect of Gelation Temperature on the Molecular Structure and Physicochemical Properties of the Curdlan Matrix: Spectroscopic and Microscopic Analyses. International Journal of Molecular Sciences, 21(17), 6154. https://doi.org/10.3390/ijms21176154

Iqbal, S., Bhanger, M.I. and Anwar, F. (2005). Antioxidant properties and components of some commercially available varieties of rice bran in Pakistan. Food Chemistry, 93(2), 265-272. https:// doi.org/10.1016/j.foodchem.2004.09.024

Klaus, A., Kozarski, M., Niksic, M., Jakovljevic, D., Todorovic, N. and Van Griensven, L.J. (2011). Antioxidative activities and chemical characterization of polysaccharides extracted from the basidiomycete Schizophyllum commune. LWTFood Science and Technology, 44(10), 2005-2011. https://doi.org/10.1016/j.lwt.2011.05.010

Kumar, R., Tapwal, A., Pandey, S., Borah, R.K., Borah,
D. and Borgohain, J. (2013). Macro-fungal diversity and nutrient content of some edible mushrooms of Nagaland, India. Nusantara Bioscience, 5(1), 1-7. https://doi.org/10.13057/nusbiosci/n050101

Lee, Y.T. and Kim, Y.S. (2005). Water-solubility of $\beta$ glucans in various edible mushrooms. Journal of Food Science and Nutrition, 10(3), 294-297. https:// doi.org/10.3746/jfn.2005.10.3.294

Lemieszek, M. and Rzeski, W. (2012). Anticancer properties of polysaccharides isolated from fungi of the Basidiomycetes class. Contemporary Oncology, 16(4), 285-289. https://doi.org/10.5114/ wo.2012.30055

Manzi, P. and Pizzoferrato, L. (2000). Beta-glucan in edible mushrooms. Food Chemistry, 68(3), 315-318. https://doi.org/10.1016/S0308-8146(99)00197-1

Mongkontanawat, N. and Wongekalak, L. (2015). Effect of Blanching on B-glucan Content of Native Mushrooms. Journal of Agricultural Technology, 11 (8), 2227-2237.

Mongkontanawat, N. and Phuangborisut, S. (2015). Product Development of Extracted Mushrooms Instant Juice with High Beta-glucan Mixture by Probiotic Lactic Acid Bacteria. International Journal of Agricultural Technology, 15(6), 959-974.

Nicolosi, R., Bell, S.J., Bistrian, B.R., Greenberg, I., Forse, R.A. and Blackburn, G.L. (1999). Plasma lipid changes after supplementation with $\beta$-glucan fiber from yeast. American Journal Clinical Nutrition, 70(2), 208-212. https://doi.org/10.1093/ ajen.70.2.208

Pirshahid, P.A., Phromtong, C., Laovitthayanggoon, S., Khamphan. Y., Hemthanon, T., Chueboonmee, P., Eiamwat, J. and Arunpairojana, V. (2011). Antiaging Cosmetics from Schizophyllum commune Fries. Thai Journal of Agricultural Science, 44(5), 242-246.

Polacios, L., Gareia-Lafuente, A., Guillamon, E. and Villares, A. (2012). Novel isolation of water-soluble polysaccharides from the fruiting body of Pleurotus ostreatus mushrooms. Carbohydrates Research, 358, 72-77. https://doi.org/10.1016/j.carres.2012.06.016 